\title{
Exploring the Potential Role of Virtual Reality in Architectural Education: College of Architecture and Planning, KSU- Case Study
}

\author{
Mohammed A. Bahobail and Dr. Abdulrahman A. Altassan
}

\begin{abstract}
The paper discusses the optional role of virtual reality (VR) in enhancing the architectural education processes at College of Architecture and Planning, King Saud University. The integration of VR in the teaching process will enhance the feeding and recalling of information by converting the classic text information to a live image story, which be implanted and recorded in the brain of the students without any effort. This digital information technique has the power to enable students to explore buildings freely and provide them with unforgettable personal experiences that enable them to dispense the referral to textual references such as architecture history books or architectural review magazines. In addition, there are many significant projects and valued buildings around the world need to be visited. By this technology, students can visit these projects and enjoy moving through its parts virtually without needs to travel or suffering from any expenses cost.

The paper highlights the importance of using VR in architecture education processes through two axes: converting classic courses to live images courses and recording important projects and historical building around the world into stereoscopic videos for documentation and exploration purposes.
\end{abstract}

Keywords- Virtual Reality, Architecture, Architectural Education, Architectural Stereoscopic Video.

\section{INTRODUCTION}

VR can mimic physical environments and provides people with similar experiences by immersing them completely or partially in virtual environments. Naturally, it requires multi-integrated system that includes a high-speed three-dimensional graphics, audio feedback, and a navigation system, in order to produce such virtual interactive environments.

In terms of education, VR's educational benefits comprises the ability to take students to live in environments that are otherwise unable to be reached, in another words, it is an approach to reach new condition, that far from our capabilities, and those not possible in the real world [1] [2].

In addition, VR gives the students capability to revisit and repeat lessons multiple times without feeling apprehension and embarrassment and making the learning process more interesting and pleasant to them, with a sense of exciting and challenging. Also, it creates a better social interaction between

\footnotetext{
${ }^{1}$ Mohammed A. Bahobail and ${ }^{2}$ Dr. Abdulrahman A. Altassan , ${ }^{1,2}$ College of Architecture and Planning King Saud University Saudi Arabia
}

students as they were reacting and sharing a same virtual world [3] [4] [5].

In terms of safety, when the situation in the real world is hard and dangerous in the real world, the Simulations in virtual reality allow us to live in the same situation while maintaining the user's lives [4].

Thus, has been enhanced by rapid development in the computer technology, which make these virtual interactive environments more realistic and close to the reality, and become more manageable to be used in as a useful education tools for medical, engineering, architecture and other knowledge [3][6] [7] [8].

\section{VR IN AN ARCHITECTURE CONTEXT}

VR technology has been applied in architecture and design visualization and construction, as well as structural analysis [9]. Architects are usually facing some difficulties to make the clients to understand the concept of the project and its sequences. These obstacles came out because the clients, often don't have the ability to understand the project by seeing a $2 \mathrm{D}$ plan or 3D model. Different studies have indicated that architects use VR as immersive design tools to model various building elements [10] [11]. Other studies has showed that VR has been utilized in various functions of building science research, [12] construction operations, [13] personnel training, end-user surveys, performance simulations [14] and building information modeling visualization [15] [16].

As mentioned earlier, VR has the ability to take user/client to live in a virtual environment, this sensation of being inside a building or project makes VR an incredibly powerful tool for communicating design concept. Therefore, VR can be utilized to let the clients to experience in projects virtually from different angles in different times of year, exactly the same way that physical project can [17].

In terms of architecture education, VR can play a very important role at all parts of the architecture education process, from creating design concept, evaluating design options and showcasing proposals, to working drawing. Furthermore, VR is not restricted for design courses, but it can be used with the other architectural courses, such as architecture history, engineering systems, and light and acoustics courses. 
Among many initiatives in the efforts of achieving the vision of the college of architecture and planning, which states:

"International excellence in building knowledge in Built Environment Sciences"

And to its accompany message which states:

"Offering excellent education and innovative scientific research that can contribute to the leadership role the university plays, and to meet the expectations of the community in the fields of Built Environment through creating a stimulating educational environment, creative and innovative workforce, supportive administrative system, and effective societal partnership"

The college has established a VR research unit equipped with advanced lab to fulfil variety of education needs for both undergraduate and graduate studies.

\section{VR LAB In COLLEGE Of ARChITECtURe AND PlanNing}

The college implemented the VR lab within the computer center, which is in the basement floor, to allow convenient access for students and faculty members and to be under supervision of the IT expertise of the computer center, Fig. 1. It is considered one of the most up-to-date labs in the world. It was designed by Barco, which is a company specialized in visual presentations. Through this Lab one may experience situations that may not be available in the real world because they are, among other things, too dangerous, too expensive or too difficult to experience for lack of sufficient time.

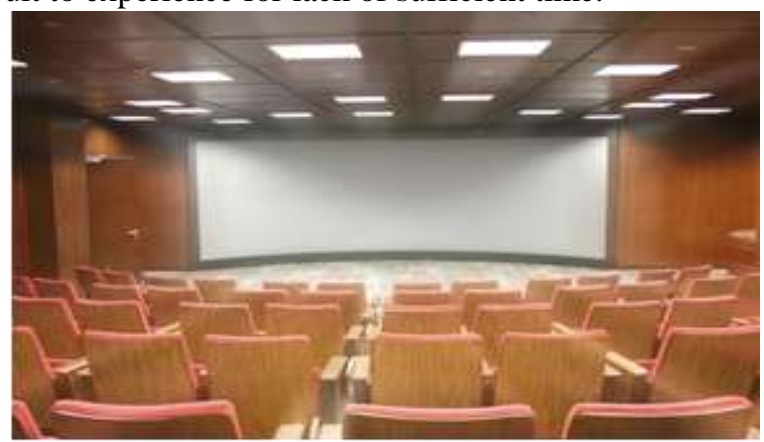

Fig. 1: VR lab in College of Architecture and Planning King Saud University

The system comprises a high-resolution and large-size presentation curve screen $(7 \mathrm{~m} \times 3 \mathrm{~m})$, with rear projection, operated by two projectors generating an image of 4 million pixels resolution, Fig. 2.

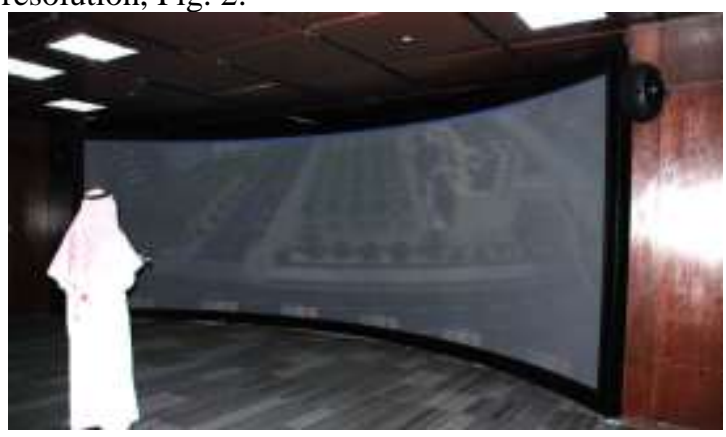

Fig. 2: large-size presentation curve screen
The projectors are edge-blended to provide a seamless image, across the entire display wall, creating an immersive environment in mono or stereo through the use of Infitec stereo. The system is loaded with sensors installed at the Lab ceiling and is used to sense the movement of the viewers. The infitec technology uses high- quality color filtering to produce a separate image for the right and left eye, achieving excellent stereo viewing with passive infitec stereo glasses. The high resolution curved screen gives the users the possibility to compare multiple image sources in native resolution at the same moment.

In addition, the system has Barco XDS-1000 Picture-in-Picture display controller which enable the user to have picture in picture functionality, which means that users can display several out puts from several computers in the same time, Fig. 3.

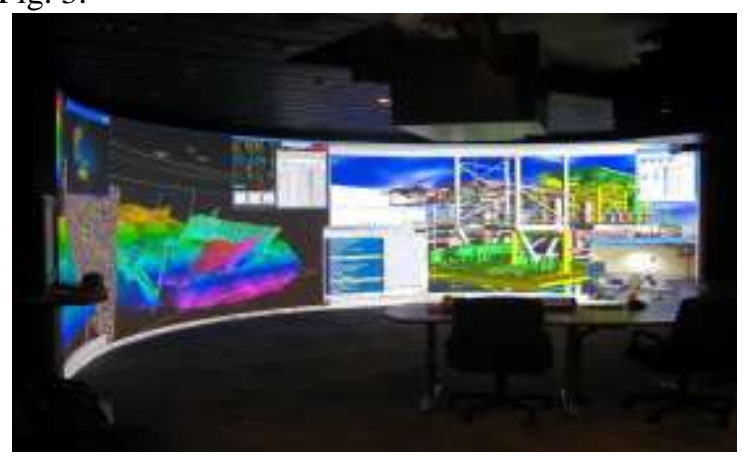

Fig. 3: Picture in Picture display

\section{VR As Learning ToOls In The College OF ARCHITECTURE AND PLANNING}

According to what mentioned above, the use of VR as a powerful tool for design process, has been discussed in several papers, and it became clear that how VR enhances the architectural design process in practice and in education field.

Similarly, VR has the ability to enrich the architecture educational experience through enhancing the comprehension and strengthening memorization, since VR utilizes all or most of sensory system. The result of a cognitive study has indicated that there are differences in the degree to which auditory, visual, and tactile memory as depicted in Fig. 4 [18].

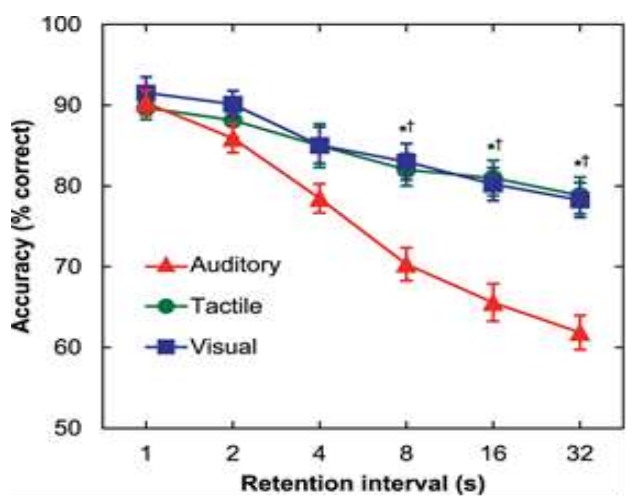

Fig. 4: Memory Retention for Sensory System 
The College of Architecture and Planning considered this within its learning system. In addition to the college has a plan to implement VR in another two approaches:

\section{A. Converting the classic lecture to virtual lecture}

Virtual lecture is an active learning process depend upon live lectures which teaching mainly through active visual/audio means, which will give the students a greater comprehension and improve their ability to recall information.

By VR, some course lectures, such as chemistry course for architectural materials, mechanical systems, sound systems and lighting, can be designed as virtual lectures containing fictional films. For example, films can be produced to explain the process of building systems, the producing architectural materials and how engineering systems work.

This idea is inspired from the film of Fantastic Voyage which about a submarine crew who shrink to microscopic size and venture into the body of an injured scientist to repair the damage to his brain [19]. Similar to that, for instance, the section of Portland cement in the course of chemistry of architectural materials can be designed as a journey of a small particles moving from the field, as a raw materials, going through production line, ending to the hand of the user. These particles play as protagonists of the film. They move, talk and interact with each other. The student, also, feel like being a part of the events and one of the film protagonists that are virtually taking place around them, Fig.5.

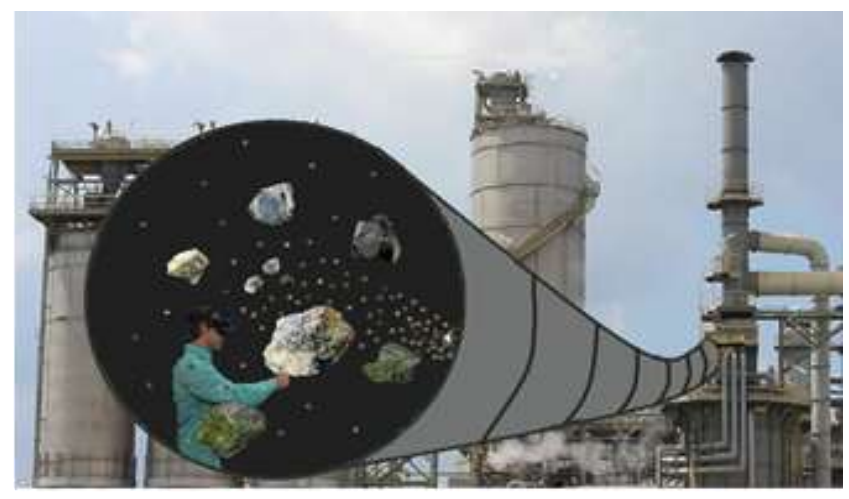

Fig. 5: virtual lecture

\section{B. Case Study (Architecture history course)}

In architecture history, VR can be an effective means of exploring the historical buildings, location and cities around the world, and it allow the students to travel into the past to visit some historical locations (buildings, cities, .....) were exist in the past centuries. They can enjoy walking through these historic places, feeling the greatness of their architectural components and learn how people used to live, and how these historical places reflect their lives.

This was proved by Ythe British Museum, where they measured the VR value and its ability to enhance the visitors' understanding of the historical collection, the Bronze Age was selected as a historical period of virtual reality, where much archaeological evidence and knowledge is not widespread. The experiment has indicated a great potential benefit for this audience [17].
The Architecture history course is under graduate course. It dealt with the architecture of prehistory and the architecture of ancient times (Paranoiac - Rafidah - Persia - Roman), and the architecture of the ages of Europe (Byzantium - Romanesque Gothic - Renaissance) as well as the architecture of the nineteenth century and the first half of the twentieth century Europe and the city of Shamala and the states of the south and east of Asa. The content of the course can be divided into three different periods of time. Each period would be designed as a separate film or virtual lecture.

The strategy to implement these virtual lectures, is consist of three stages:

\section{Stage \#1}

Converting the content of the course, buildings, places, people, events......, to acts and scenes. These acts and scenes will be outlined in order to let the students understand how to interpret the events they see. Expand this outline by writing the scenario of the film (virtual lecture).

\section{Stage \#2}

This stage is a technical step, which needs a technical person to draw all non-exist objects (building, landmark, sculptures ...etc.) in a $3 \mathrm{~d}$ model with a high rendering level.

\section{Stage \#3}

For the existing objects, like some famous and historical buildings, these will be visited and recorded into stereoscopic video, by using a stereoscopic camera. The stereoscopic camera is a camera with two lenses that can capture any scenes and recorded it into stereoscopic format which can be seen directly through VR system, Fig. 6.

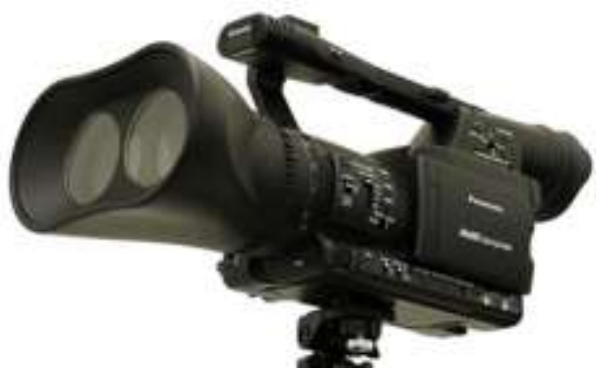

\section{Stage \#4}

Fig. 6: Stereoscopic Camera

The $3 \mathrm{~d}$ models, and stereoscopic videos, text and sound will be combined based on the scenario of the film and converted to virtual reality film using a "Virtool" software. The final output should be reviewed and evaluated several times to correct any mistake or to improve its quality.

The expected advantages are:

- Enhance Memorizing information and events through enjoyable process, due to the learning environment which is much more memorable than text or static 2D images.

- Seeing the world through virtual reality will improve cognition and understand reality.

- Seeing the historical nations virtually provides an education that teach a mix of knowledge, such as economy, history, geography, and sociology within a very short time and through a distinct mental image.

- By exploring architectural projects, students will find themselves adventurous, eager to look for all new knowledge. 
Finally, these stages require considerable effort and time, but it may be easy to start by a small part of this course as a pilot study. Then it will be easy to update it to cover all parts of the course.

\section{VR and Summer Training}

Each year, the College of Architecture and Planning offers a summer training program as part of the curriculum requirement, in order to help students to hone their skills and provide a detailed look at the professional work. There are several training companies and offices, around the world, that provide training programs. But, usually these companies and offices are limited and expensive. For example, the cost of abroad summer training program for the academic year 2007-2008 exceeds $\$ 225,000$, and the trainees have been nominated to reputable firms in Australia, Singapore, Germany, Italy, Spain, and United States of America. Unfortunately, the high cost of such training program forfeits the opportunity for many students to benefit from the exposure to rich practical experiences and guided by reputable experts

To overcome this problem, the VR can be utilized to connect the students with office staff through video conference, which provided by the system, and transfer the student to the office projects through virtual reality by using stereoscopic camera, as mentioned before. With this technique, the college can train unlimited number of students, free of charge and without any expenses. In addition, training in VR allows the college to expose its students to a different kind of experiences, in different part of the world without putting them in risk and without need to travel. So, VR makes training program more convenient by saving college' time as well as budget.

\section{CONCLUSION}

This paper has discussed, on general, the use of VR on education, and how its effect on the learning process. The main aim of this study restricted on focusing on how to implement VR in teaching architecture courses in the college of architecture and planning at King Saud University. The paper, also, explored the potential for VR as a tool to produce a virtual lecture to substitute the classic lecture, which will be more effective and informative in an enjoyable learning atmosphere.

In addition, the paper explained how to enhance the training summer course by using VR technology, which will reduce the cost and increase the number of trainees. General, the study indicates that VR has the potential to enhance the processes of architectural education; however, the initial phase requires a lot of work from the research unit's members and administrative support from the college deanship, and eventually the work of the unit would be update gradually by the time.

\section{REFERENCES}

[1] A. Antonietti, M. Cantoia, "To see a painting versus to walk in a painting: experiment on sense-making through virtual reality", Computers \& Education, 34 (2000) 213-223. HTTPS://DOI.ORG/10.1016/S0360-1315(99)00046-9

[2] B. Chavez, S. BAyona, "Virtual Reality in the Learning Process", BOOK: TRENDS AND ADVANCES IN INFORMATION SYSTEMS AND TECHNOLOGIES, March 2018.

[3] https://theconversation.com/how-virtual-reality-technology-is-changingthe-way-students

[4] S. D. Piovesan1, L. M. Passerino1 and A. Soares Pereira2, "Virtual Reality as a Tool in the Education", IADIS International Conference on Cognition and Exploratory Learning in Digital Age (CELDA 2012).

[5] V. S. Pantelidis, Reasons to Use Virtual Reality in Education and Training Courses and a Model to Determine When to Use Virtual Reality, THEMES IN SCIENCE AND TECHNOLOGY EDUCATION Special Issue, Pages 59-70 Klidarithmos Computer Books, Vol 2, No 1-2 (2009)

[6] M. Emilio, P. Shyam, C. Juan, P. Hernandez, "Introducing a Virtual Reality Experience in Anatomic Pathology Education", American Journal of Clinical Pathology, Volume 146, Issue 4, 1 October 2016, Pages 462-468.

[7] P. Poorang, E. Amer, B. Simon, R. Eric, J. Ruoyu, "Augmented Reality (AR) and Virtual Reality (VR) in construction industry: An experiential development workflow", The Tenth International Conference on Construction in the 21st Century (CITC-10) July 2nd-4th, 2018, Colombo, Sri Lanka.

[8] E. Diaz-Perez, J. A. Florez-Lozano, "Virtual reality and dementia", May 2018 Revista de neurologia 66(10):344-352

[9] P. Wang, P. Wu, J. Wang, H. Chi, X. Wang, "A Critical Review of the Use of Virtual Reality in Construction Engineering Education and Training", International Journal of Environmental Research and Public Health, 15(6):1204, June 2018 https://doi.org/10.3390/ijerph15061204

[10] "vSpline". www.vspline.com. Archived from the original on 2017-09-19. Retrieved 2017-11-09.

[11] "VR - Gravity Sketch". Gravity Sketch. Archived from the original on 2017-01-15. Retrieved 2017-11-09.

[12] Kuliga, S.F.; Thrash, T.; Dalton, R.C.; Hölscher, C. "Virtual reality as an empirical research tool - Exploring user experience in a real building and a corresponding virtual model". Computers, Environment and Urban Systems. 54:

363-375. doi:10.1016/j.compenvurbsys.2015.09.006. Archived from the original on 2018-05-03.

[13] K. Vineet R.; M. Julio"Visualizing Simulated Construction Operations in 3D". Journal of Computing in Civil Engineering. . (2001). 15 (4): 329-337. doi:10.1061/(asce)0887-3801(2001)15:4(329).

[14] Malkawi, M. Ali., Srinivasan, S. Ravi, "A new paradigm for Human-Building Interaction: the use of CFD and Augmented Reality". Automation in Construction. 14 (1): 71-84. doi:10.1016/j.autcon.2004.08.001.

[15] "Revit Live | Immersive Architectural Visualization | Autodesk". Archivedfrom the original on 2017-11-09. Retrieved 2017-11-09.

[16] "IrisVR - Virtual Reality for Architecture, Engineering, and Construction". irisvr.com. Retrieved 2017-11-09.

[17] J. RAE, "Virtual reality at the British Museum: What is the value of virtual reality environments for learning by children and young people, schools, and families? "BRITISH Museum, UK, LiZZIE EdwARdS, THE BRITISH MUSEUM, ENGLAND

[18] J. Bigelow, A. Poremba, Achilles' Ear? "Inferior Human Short-Term and Recognition Memory in the Auditory Modality". (2014), HTTPS://DOI.ORG/10.1371/JOURNAL.PONE.0089914

[19] D. Fischer, Science Fiction Film Directors, 1895-1998. McFarland. (2000) p. 192. ISBN 0-7864-0740-9. 